\title{
An Investigation of the Effect of Ventilation Inlet and Outlet Arrangement on Heat Concentration in a Ship Engine Room
}

\author{
E. Alizadeh \\ Malek Ashtar University of \\ Technology (MUT) \\ Fereydunkenar, Iran \\ ealizadeh@mut.ac.ir
}

\author{
A. Maleki \\ Malek Ashtar University of \\ Technology (MUT) \\ Fereydunkenar, Iran \\ amaleki@gmail.com
}

\author{
A. Mohamadi \\ Malek Ashtar University of \\ Technology (MUT) \\ Fereydunkenar, Iran
}

\begin{abstract}
The ventilation in the ship engine rooms is an essential issue concerning finest performance of engines and diesel generators as well as electric motors. The present study has aimed at the analysis of temperature distribution inside the ship main engine room. In the same way, attempts have been made to identify those points with considerable thermal concentration in main engine room space, so that proper ventilation systems could be engineered and utilized and favorable thermal conditions could be realized. The CFD approach has been utilized in order to analyze impact of the designed ventilation system on the temperature distribution pattern. The Inlet layout and area have been analyzed under a variety of scenarios in order to decrease the average temperature and eliminate the heat concentrations in various points of the engine room. The temperature distribution and location and area of ventilation air inlet have been studied in different modes resulted in temperature distribution pattern, heat concentration outline and average volumetric temperature level in each mode. The results indicated that considerable circulating air volume is required compared to those levels suggested by common practices, calculations and standards in order to eliminate the heat concentration.
\end{abstract}

Keywords-surface ship; engine room ventilation; thermal analysis; heat analysis; naval

\section{INTRODUCTION}

Main and auxiliary engine rooms are of the main areas in a military floating ship containing lots of equipment, machineries, electrical gears and major engines and thus require proper ventilation under various severe weather conditions. Ventilation of engine rooms is essentially important and follows a series of objectives including supply of air to engines for combustion purposes, heat transfer through convection and airflow for recovery and outflow of undesirable heat, fixing the temperature in a specific interval so that crews could operate there and electrical appliances be kept away from substantial thermal exposure [1]. There are few studies conducted on application of CFD in ventilation of marine engine rooms despite the importance of such analysis. Authors in [2] estimated the thermal profile of a marine ship's engine room through simulation techniques and measuring approaches using in-field data gathering. The experimental data were integrated to CFD model for a thermal analysis under various applications. They made use of CFD approach for modeling of the Ventilation system in a marine ship under operation in order to monitor the systems performance improvement (under severe weather conditions) that had the potential of higher efficiency of its engines and generators. They were focused on inlets and outlets to conduct the air flow and accordingly convection process in the room in order to enhance the efficiency of the engines and generators. Operation conditions and average temperature suitable for crews as well as efficiency level of the engines had been selected as the performance indicators in their study. Authors in [3] have conducted $3 \mathrm{D}$ simulation of the ventilation system in a closed engine room using CFD. Their test results were in accordance with the estimations generated through the experimental formulations. Authors in [4] conducted the ventilation analysis in a ship engine room. CFD analysis was included in the study in order to estimate the air flow in the engine room and use of results as a reference for locating the smoke sensors. Internal air flow pattern could be resulted from analysis output. Author in [5] also analyzed the simulation and optimization of ventilation system of a ship engine rooms. Theory-based principles were applied in ventilation system design of the study. In addition, the CFD approach was utilized to investigate the conditions of engine room ventilation. The study analyzed and simulated the flow and temperature patterns in the engine room and resulted in an optimum design for the ventilation system. Author in [6] simulated the temperature and flow pattern in the ship engine room. The study was conducted using the CFD approach in a ship engine room. Simulation of the ventilation system resulted in flow rate and temperature distribution pattern in the engine room. In [7], author applied the numerical simulation approach to analyze the air flow distribution in the marine engine room. Analyzing a ship engine room as a research objective, he simulated the ventilation system using CFD and analyzed the simulation results in detail. Authors in [8] utilized CFD for air flow 
analysis in the ship engine room. The simulation presented in their study provides a clear view of the airflow distribution in the engine room. There are other similar studies conducted in the field of CFD analysis in the engine room including research and investigations made by authors in [9-12]. Objective of the present study is to investigate the temperature distribution in the engine room; hence attempts have been made here to identify points with high level of heat concentration so that appropriate ventilation systems could be designed in order to realize a proper temperature condition. The CFD approach is also utilized in the present study to investigate the impact of ventilation system design on the temperature distribution pattern.

\section{NUMERICAL AND GEOMETRICAL MODELING OF THE ENGINE ROOM}

\section{A. Engine room geometry}

The ship studied in the present paper has two engine rooms equipped with $2850 \mathrm{~kW}$ diesel generator and $19500 \mathrm{~kW}$ Turbocompressor. Figure 1, shows one of the engine room interior arrangements with main engine and auxiliary equipment.

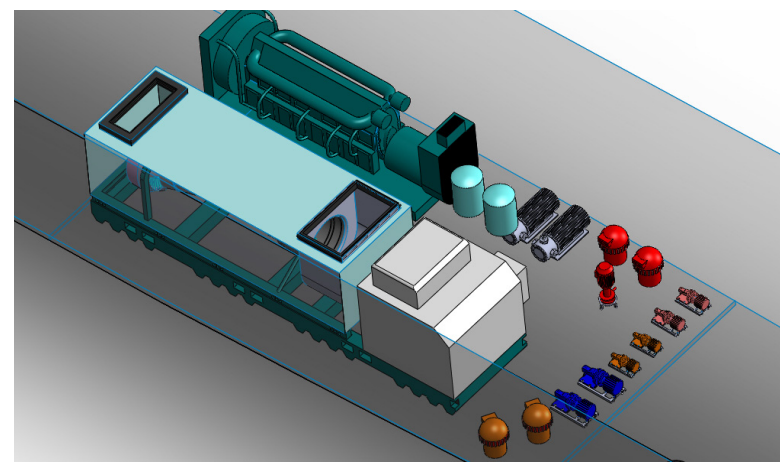

Fig. 1. Equipment arrangement in ship engine room In this engine room expect of main engines and their exhaust pipes, there is some auxiliary machinery that includes fuel pumps and purifier, lubrication pumps and purifier, firefighting pump, air compressor etc.

\section{B. Engine Room Heat Source}

All engines and auxiliary equipments are source of heat that can be released to engine room space. Each engine heat transfer to the space is described as follows.

a) Electric Generators

Considering 97\% efficiency level of the main engines (turbine \& Diesel) water cooled generators, there is $3 \%$ capacity loss. Since $0.25 \%$ of the capacity loss in the watercooled generators has been released to engine room [13], it could be concluded that the heat transfer equals to $48 \mathrm{KW}$ and $7 \mathrm{KW}$.

\section{b) Diesel Engine}

Considering the diesel engine catalogue presented by Caterpillar Company, the heat radiation to the engine room equals to $128 \mathrm{KW}$.

c) Gas-Turbine
Gas turbine structure differs considerably from diesel engine. Gas turbine equipment is located in a box with specific air inlet and outlet. The inlet air serves as the cooling agent for the gas turbine in addition to supply of the air required in the combustion chamber. It should be noted that the box input air for turbine needs is supplied through a specific vent that has nothing to do with the engine room's air inlets. Gas turbine box is internally (thermal \& acoustic) isolated. Considering various electrical appliances exist in the gas turbine box, the temperature level is somehow stable. Structure of turbine box and this air inlet and outlet is showed in Figure 2. Each side of the gas turbine has its own temperature which is calculated through simulation and varies between $308 \mathrm{~K}$ and $317 \mathrm{~K}$ and the average amount is $310 \mathrm{~K}$.

TABLE I. HEAT RADIATION OF DIESEL ENGINE TO ATMOSPHERE

\begin{tabular}{|c|c|c|c|c|c|c|c|}
\hline & Cylinder & \multicolumn{2}{|c|}{6} & \multicolumn{2}{|c|}{8} & \multicolumn{2}{|c|}{9} \\
\hline Fresh water cooling & \multirow[b]{2}{*}{$\mathrm{m}^{3}$} & \multirow{2}{*}{\multicolumn{2}{|c|}{0.4}} & \multirow{2}{*}{\multicolumn{2}{|c|}{0.5}} & \multirow{2}{*}{\multicolumn{2}{|c|}{0.6}} \\
\hline Engine content & & & & & & & \\
\hline Pressure at engine inlet $\min / \max$ & bar & \multicolumn{2}{|c|}{$2.5 / 6.0$} & \multicolumn{2}{|c|}{$2.5 / 6.0$} & \multicolumn{2}{|c|}{$2.5 / 6.0$} \\
\hline Header tank capacity & $\mathrm{m}^{3}$ & \multicolumn{2}{|c|}{0.2} & \multicolumn{2}{|c|}{0.25} & \multicolumn{2}{|c|}{0.3} \\
\hline Temperature at engine outlet & ${ }^{\circ} \mathrm{C}$ & \multicolumn{2}{|c|}{$80-90$} & \multicolumn{2}{|c|}{$80-90$} & \multicolumn{2}{|c|}{$80-90$} \\
\hline Two circuit system & \multirow{6}{*}{$\begin{array}{c}\mathrm{m}^{3} / \mathrm{h} / \mathrm{bar} \\
\mathrm{m}^{3} / \mathrm{h} / \mathrm{bar} \\
\mathrm{mm} \\
\mathrm{m}^{3} / \mathrm{h} \\
{ }^{\circ} \mathrm{C}\end{array}$} & \multirow{2}{*}{\multicolumn{2}{|c|}{$40 / 3.7$}} & \multirow{2}{*}{\multicolumn{2}{|c|}{$55 / 3.5$}} & \multirow{2}{*}{\multicolumn{2}{|c|}{ 60/3.7. }} \\
\hline Engine driven pump $\mathrm{HT}$ & & & & & & & \\
\hline Independent pump HT & & \multicolumn{2}{|c|}{$40 / 3.0$} & \multicolumn{2}{|c|}{$55 / 3.0$} & \multicolumn{2}{|c|}{$60 / 3.0$} \\
\hline HT-Controller DN & & \multicolumn{2}{|c|}{80} & \multicolumn{2}{|c|}{100} & \multicolumn{2}{|c|}{100} \\
\hline Water demand LT-charge air cooler & & \multicolumn{2}{|c|}{40} & \multicolumn{2}{|c|}{45} & \multicolumn{2}{|c|}{50} \\
\hline $\begin{array}{l}\text { Temperature at LT-charge air } \\
\text { cooler inlet }\end{array}$ & & \multicolumn{2}{|c|}{38} & \multicolumn{2}{|c|}{38} & \multicolumn{2}{|c|}{38} \\
\hline Heat Dissipation & \multirow{6}{*}{$\begin{array}{l}\mathrm{kJ} / \mathrm{kWh} \\
\mathrm{kJ} / \mathrm{kWh} \\
\mathrm{MJ} / \mathrm{h} \\
\mathrm{MJ} / \mathrm{h} \\
\mathrm{MJ} / \mathrm{h}\end{array}$} & \multirow{3}{*}{\multicolumn{2}{|c|}{$\begin{array}{l}500 \\
490\end{array}$}} & \multirow{3}{*}{\multicolumn{2}{|c|}{$\begin{array}{l}500 \\
490\end{array}$}} & & \\
\hline Specific jacket water heat & & & & & & & 00 \\
\hline Specific lub. oil heat & & & & & & & 90 \\
\hline Lub. oil cooler & & 931 & 970 & 1242 & 1294 & 1396 & 1455 \\
\hline Jacket water & & 950 & 990 & 1267 & 1320 & 1425 & 1485 \\
\hline Charge air cooler (HT-Stage) ${ }^{3}$ & & 2160 & 2255 & 2808 & 2934 & 3096 & 3240 \\
\hline 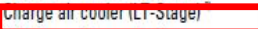 & TVIJIII & 020 & 804 & $\pi 170$ & 7110 & 7200 & 7200 \\
\hline (HI-Stage atter engine) & & & & & & & \\
\hline Heat radiation engine & $\mathrm{MJ} / \mathrm{h}$ & & 06 & & & & 60 \\
\hline
\end{tabular}

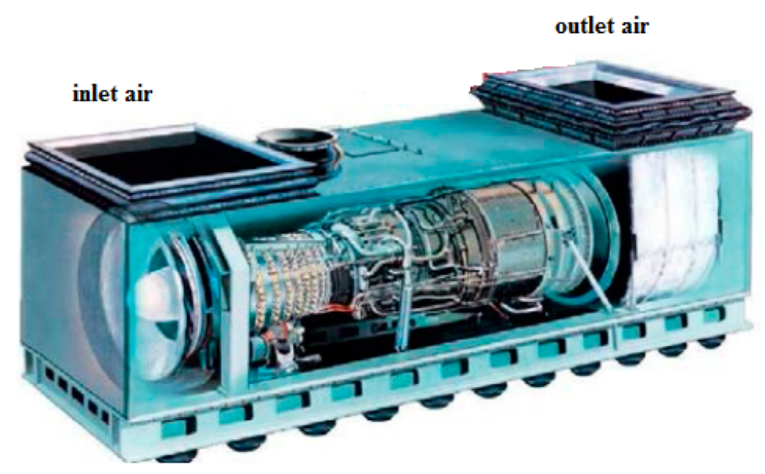

Fig. 2. Gas turbine box and inlet and outlet of air. To assess the shell temperature of the turbine module, turbine box is modeled in the GAMBIT which is called later in the FLUENT. It is assumed that the air flows through the module under $308 \mathrm{~K}$ temperature and $3 \mathrm{~kg} / \mathrm{s}$ mass rate. Following the simulation process, the average temperature contour of the module shell could be illustrated as Figure 3.

\section{d) Exhaust Pipes}

The heat emissions from two exhaust pipes are determined from the curve presented in ISO8861 [1]. According to the total lengths of exhaust pipes, the total heat emission to the engine room is calculated to be $5 \mathrm{KW}$. 
e) Auxiliary Machineries

Auxiliary machinery and equipment in the engine room operate under $100 \mathrm{~kW}$ nominal capacity. By considering ISO8861, there is a $20 \%$ loss of capacity assumed in the engine room (i.e. $20 \mathrm{~kW}$ ) that is added to loss of diesel engine.

f) Sum of Heat Radiations

Calculated heat radiations from engines, generators and other heat sources in engine room are listed in Table II.

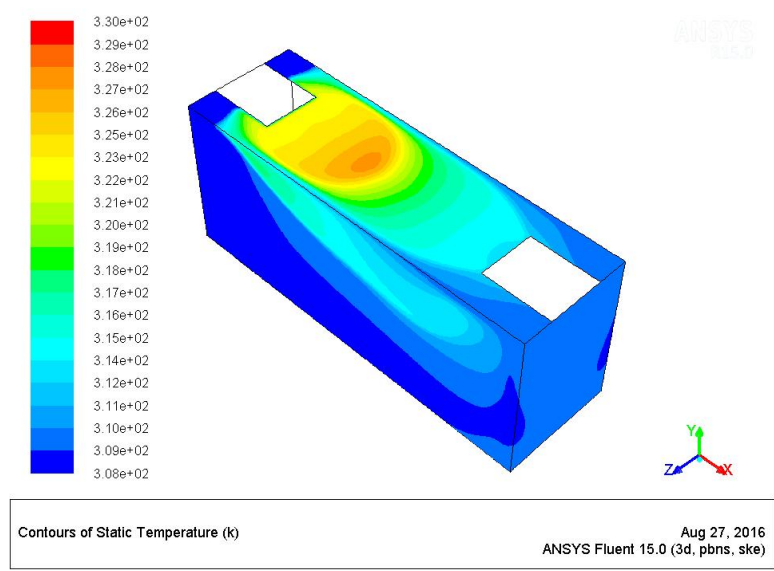

Fig. 3. Gas turbine module temperature contour

TABLE II. THERMAL RADIATION OF ENGINE ROOM AUXILIARY MACHINERIES

\begin{tabular}{|c|c|}
\hline Equipment & $\begin{array}{c}\text { Heat Radiation } \\
(\mathbf{k W})\end{array}$ \\
\hline Generator (For Turbine) & 45 \\
\hline Generator (For Diesel) & 7 \\
\hline Gas Turbine & 8.9 \\
\hline Diesel Engine & 128 \\
\hline Exhaust Pipes & 5 \\
\hline Auxiliary machineries & 20 \\
\hline Sum of heat radiation & 205.6 \\
\hline
\end{tabular}

\section{Boundary Condition}

Boundary condition of ventilation air inlet and outlet identifies velocity inlet and pressure outlet. The lateral and side walls of the ship engine room known as "Wall" are exposed to convection heat transfer. Since part of the side wall is in contact with water and the other part is in touch with air, it is analyzed separately. Wall boundary condition of the diesel generators, turbine generators and diesel engines are the system walls with heat flux. Constant temperature on the side wall is set as the turbine wall boundary condition. Wall of the turbine and diesel engine exhaust pipe are set as the boundary condition shell with a $6 \mathrm{~mm}$ insulation thickness. Bundary conditions and their description are shown in Table III.

\section{Governing Equations}

In this study; continuity equations, momentum conversation equations and energy conversation equations for steady state and incompressible flows in conjunction with buoyancy effects from Boussinesq approximation are used for the analysis.

TABLE III. BOUNDARY CONDITION DESCRIPTION

\begin{tabular}{|c|c|c|}
\hline Boundary & Condition Type & Condition Value \\
\hline Air inlet & Velocity Inlet & $5 \mathrm{~m} / \mathrm{s}$ \\
\hline Air Outlet & Pressure Outlet & $1 \mathrm{~atm}$ \\
\hline Side Wall & Wall & $\begin{array}{c}\text { Convection heat transfer } \\
\text { coefficient for } 10 \\
\mathrm{~W} / \mathrm{m}^{2} . \mathrm{K} \text { and } 15 \mathrm{~W} / \mathrm{m}^{2} . \mathrm{K} \\
\text { for air and water } \\
\text { respectively }\end{array}$ \\
\hline Lateral Wall & Symmetry \\
\hline $\begin{array}{c}\text { Diesel Engine } \\
\text { Surface }\end{array}$ & Wall (Constant flux) & $1316\left(\mathrm{~W} / \mathrm{m}^{2}\right)$ \\
\hline $\begin{array}{c}\text { Gas Turbine } \\
\text { Surface }\end{array}$ & Wall (Constant & $310 \mathrm{~K}$ \\
\hline $\begin{array}{c}\text { Generator (For } \\
\text { Diesel) }\end{array}$ & Wall (Constant flux) & $133.48\left(\mathrm{~W} / \mathrm{m}^{2}\right)$ \\
\hline $\begin{array}{c}\text { Generator (For } \\
\text { Turbine) }\end{array}$ & Wall (Constant flux) & $732.6\left(\mathrm{~W} / \mathrm{m}^{2}\right)$ \\
\hline $\begin{array}{c}\text { Exhaust } \\
\text { Surface }\end{array}$ & $\begin{array}{c}\text { Wall (Constant } \\
\text { Temperature) }\end{array}$ & $\begin{array}{c}350 \mathrm{~K}(\mathrm{Gas} \mathrm{Turbine}), \\
343 \mathrm{~K}(\mathrm{Diesel} \mathrm{Engine)}\end{array}$ \\
\hline
\end{tabular}

Continuity Equation:

$$
\nabla \cdot \vec{v}=0
$$

Momentum Conversation Equation:

$$
\rho(\vec{v} \cdot \nabla \vec{v})=-\nabla p+\nabla^{2} \vec{v}+\vec{S}
$$

Energy Conversation Equation:

$$
\rho c_{p}((\vec{v} . \nabla) T)=k \nabla^{2} T+S_{T}
$$

where: $\mathrm{S}$ is the buoyancy force which affects the fluids and is derived from the Boussinesq approximation:

$$
\vec{S}=\rho \vec{g}\left[1-\beta\left(T-T_{r e f}\right)\right]
$$

For ventilation of engine room, ISO8861 [1], proposes some equations. Equation (5) defines the total amount of air needed for the ventilation:

$$
\begin{aligned}
& Q=q_{c}+q_{h} \\
& q_{h}=\frac{\Phi_{h}}{\rho \times c \times \Delta T} \\
& q_{c}=\frac{P_{d g} \times m_{a d}}{\rho}
\end{aligned}
$$

$\mathrm{Q}$ in (5) is the total volume of air needed for the ventilation of engine room, $q_{c}$ and $q_{h}$ are the total air volume for combustion and for evacuation of heat emission respectively. $\Phi_{h}$ is the total amount of thermal emission from all equipment which is given in Table II. $\rho, c, \Delta T$ are the density of air, specific heat capacity of air and the difference between inlet and outlet air at design conditions. $p_{d g}$ is the power of the engine room and $m_{a d}$ is the air requirement for diesel engine combustion, in kilograms per kilowatt second. For investigating the thermal concentration in engine room, a dimensionless parameter, $\eta$, is defined as below: 


$$
\eta=\frac{V_{h} T_{h}}{V_{t} T_{m}}
$$

$V_{h}$ is the volume of space in engine room in which the temperature exceeds $55^{\circ} \mathrm{C}$ (hot zones), $T_{h}$ is the temperature in hot zones, $V_{t}$ is the total volume of engine room and $T_{m}$ is the average temperature of the engine room. Considering ISO 8861, temperature difference between air flow inlet and outlet in the engine room (while engines and other auxiliary are operating) should not exceed $12.5^{\circ} \mathrm{C}$. It should be noted that the input air temperature has been set on $37^{\circ} \mathrm{C}$ in the present study due to the ship's geographical coordination.

\section{TABLE IV. SUM OF THE AIRFLOW FOR ENGINE ROOM VENTILATION}

\begin{tabular}{|c|c|c|}
\hline Equipment & $\begin{array}{c}\text { Cooling } \\
\text { Airflow } \\
\left(\mathbf{m}^{\mathbf{3}} / \mathbf{s}\right)\end{array}$ & $\begin{array}{c}\text { Combustion } \\
\operatorname{Airflow}\left(\mathbf{m}^{\mathbf{3}} / \mathbf{s}\right)\end{array}$ \\
\hline Diesel Engine & 8.97 & 5.31 \\
\hline Gas Turbine & 0.62 & - \\
\hline Generator (For Diesel) & 0.5 & - \\
\hline Generator (For Turbine) & 3.15 & - \\
\hline Exhaust Pipe & 0.35 & - \\
\hline Auxiliary Machinery & 1.4 & - \\
\hline
\end{tabular}

\section{SiMULATION}

Initial inlet arrangement should be identified in advance to start the simulation process. The engine room is first simulated regardless of any vents in order to provide us with the best initial proposal so that warmer areas could be identified and accordingly initial vent layout could be arranged close to the proposed points. At the first phase the engine room is modeled regardless of any inlet and outlet air vent in order to identify critical and heat zone. The modeling showed that critical point and hot zones are close to the main heat sources. Considering the first phase approach (without vents), the temperature level above the diesel engine is higher than other zones. In addition, since the combustion air of the engine diesel is directly supplied through the air exits in the engine room, most of the engine manufacturers/vendors suggest that the air inlet should be positioned close to the diesel engine super charger. It should be noted that a variety of positioning and sizes of the inlet and outlet have been considered in the present study for the ventilation of the engine room. The simulation is carried out with an inlet and an outlet vent and accordingly various scenarios have been analyzed in this case based on changes in the layout. Initial layout has been arranged in accordance with the heat concentration pattern as shown in Figure 4. The scenarios mentioned above will be analyzed further in detail.

\section{A. Single Inlet Area of $4.5 \mathrm{~m}^{2}$}

a) Case 1

Inlet is located above the Diesel Engine and outlet is located close to the diesel engine on the engine room ceiling (Figure 5). In this case, highly heat concentration levels are observed above the diesel engine and the associated generator. On the other hand, the generator is exposed to heat concentration due to its distance from the vent. Thus the vent is positioned to another point in the next layout to be located somewhere closer to both generator and top of the diesel. So the vent is positioned on the ceiling center and somewhere between the generator and diesel generator. However, it should be noted that considerable heat concentration does not increase again and exceed acceptable level. Hence this task is carried out with care in multiple stages. In the next step the vent position is closer to the ceiling center and the turbine generator.

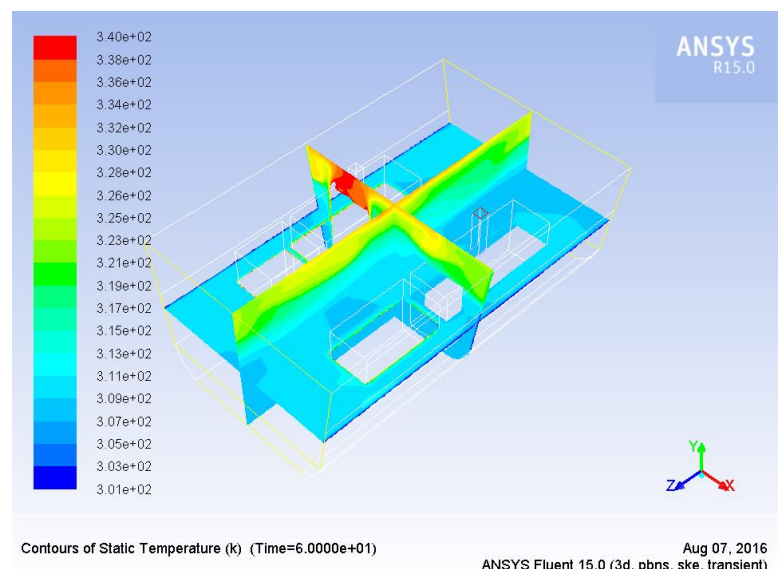

Fig. 4. Isometric view of temperature contours of engine room with no inlet and outlet

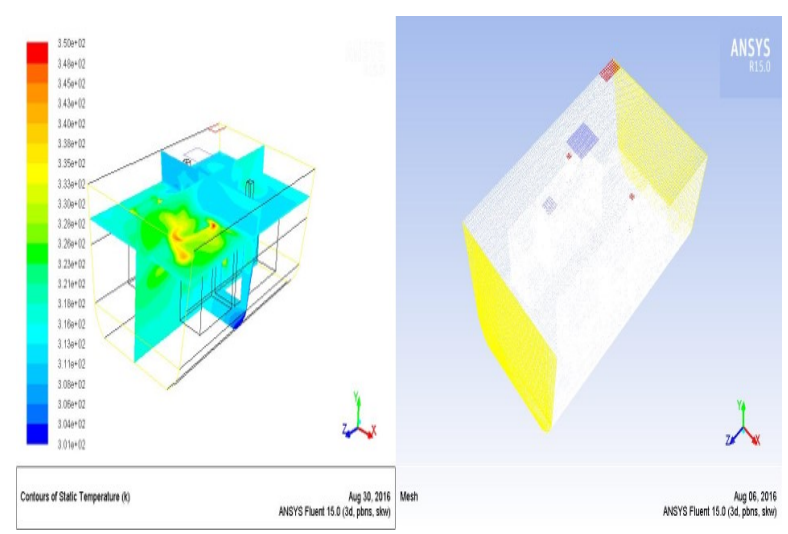

Fig. 5. Isothermal contours of temperature and mesh of case 1

b) Case 2

Inlet is located in the ceiling center and Outlet is at corner near the diesel engine (Figure 6). Average temperature level in this case is 4 degrees lower compared to the previous case however heat concentration above the generator (for diesel) and generator (for turbine) remained the same. Decrease in the average temperature indicates that increase in distance between vents inlet and outlet leads to better circulation of the air enter in the engine room and accordingly decrease in the average temperature. However, heat concentration above the generator (diesel \& turbine) has remained the same. Therefore, attempts have been made in the next step to increase the distance even more compared to the case 2 , so the next position could be suggested above the turbine generator. 


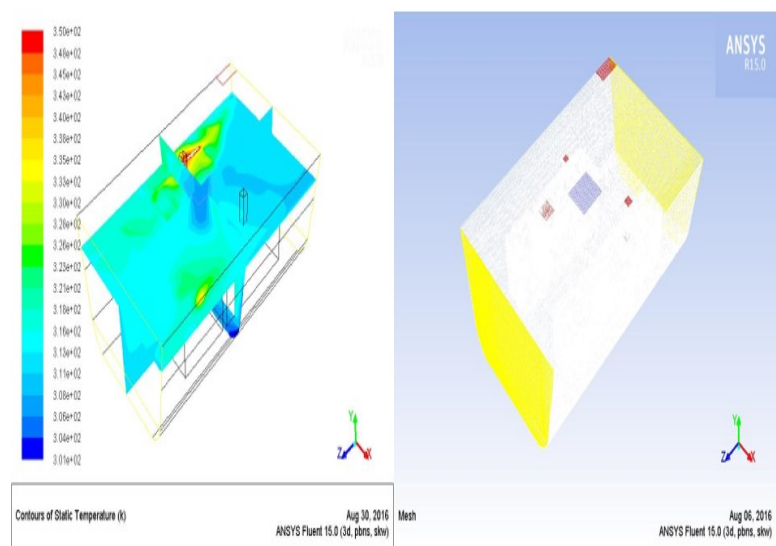

Fig. 6. Isothermal contours of temperature and mesh of case 2

c) Case 3

Inlet is located above the generator (for turbine) and output is located close to the diesel engine on the engine room ceiling (Figure 7). Average temperature in this case is lower than the two cases mentioned above, however the only drawback to this layout could be stated as the increase in the heat concentration around the diesel engine where supplies the air required for combustion purposes. Increase in air temperature around the diesel engine and accordingly increase in the combustion air temperature leads to loss of engine efficiency. Simulation of cases 1,2 and 3 shows that it is unlikely to eliminate heat concentration in all points. Positioning the inlet above the diesel engine leads to heat concentration in south part of the generator (for turbine) and above the generator (for diesel) \& generator (for turbine). Considering the velocity contours, heat concentration takes place in the south part of the generator (for turbine) due to improper circulation of the input air in the area. Positioning the inlet vent in the middle of the ceiling decreases the average temperature compared to the case 1. Considering larger distance between inlet \& outlet in this case and better air circulation in the engine room, this issue is both feasible and justifiable. Besides, heat concentration in the south part of the generator (for turbine) is disappeared though it stays the same in the area above the machineries and equipment. Positioning the inlet vent above the generator (for turbine) decreases the average temperature again while removing the heat concentration above the generator (for turbine). However, increase in heat concentration in the north part of the generator (for diesel) may lead to loss of the diesel engine efficiency. In addition, heat concentration above the generator (for diesel) stays the same. Simulation results in this case are listed in Table V.

TABLE V. RESULTS FOR CASES 1-3

\begin{tabular}{|c|c|c|c|}
\hline Parameter/Case & C.1 & C.2 & C.3 \\
\hline Inlet velocity (m/s) & 5 & 5 & 5 \\
\hline Inlet Area (m $\mathbf{( m}^{\mathbf{2}}$ & 4.5 & 4.5 & 4.5 \\
\hline Outlet Area (m) & 2 & 2 & 2 \\
\hline Average temperature (K) & 318.5 & 314.5 & 312.4 \\
\hline Heat concentration & 0.18 & 0.1 & 0.14 \\
\hline
\end{tabular}

Considering the simulations mentioned above, it could be concluded that the $4.5 \mathrm{~m}^{2}$ single inlet case study does not meet the engine room requirements. Therefore, the inlet area is divided into two equal parts in the next step to evaluate various positioning and layouts. There are two inlets for the ventilation air, each of which is $2.25 \mathrm{~m}^{2}$ for simulation of this case that conduct the $308 \mathrm{~K}$ air to the engine room.

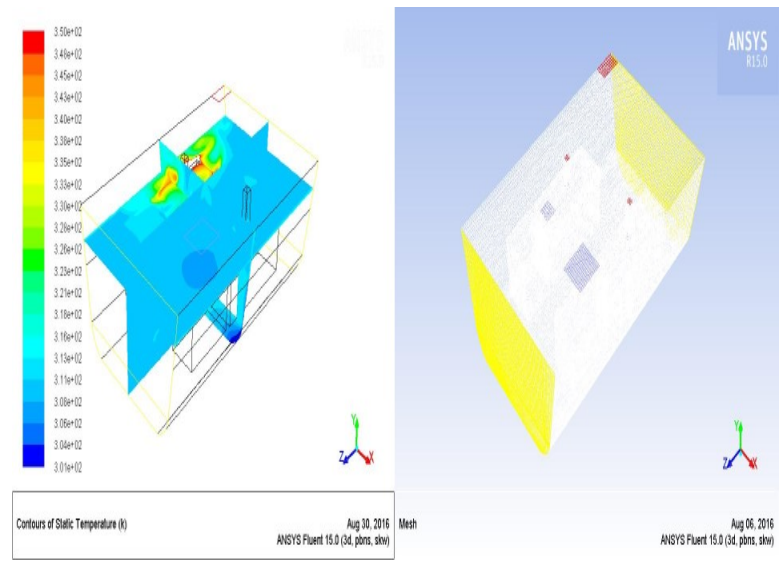

Fig. 7. Isothermal contours of temperature and mesh of case 3

\section{B. Two Inlet Areas of $2,25 \mathrm{~m}^{2}$}

\section{a) Case 4}

Both inlets are above the engine diesel and in middle of the room and outlet's output is located close to the diesel engine on the engine room ceiling (Figure 8). Although the heat concentration in this case has been considerably removed, the concentration above two generators and among machineries and equipment stay the same. Next vent positioning is suggested in the middle of the ceiling and above the generator (for turbine) to decrease the temperature level around the generator (for turbine).

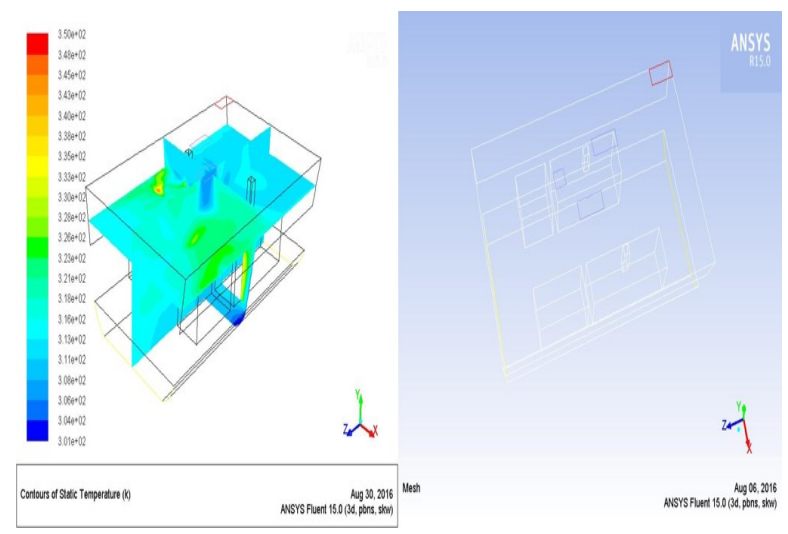

Fig. 8. Isothermal contours of temperature and mesh of case 4

b) Case 5

Inlets are In the middle of the ceiling and above the generator (for turbine) and outlet's output is located close to the diesel engine on the engine room ceiling (Figure 9). Heat 
concentration points around the diesel engine still exist in this case due to lack of a vent above the diesel engine. Therefore, inlets are positioned in the diesel engine and the generator (for turbine) in the next positioning layout.

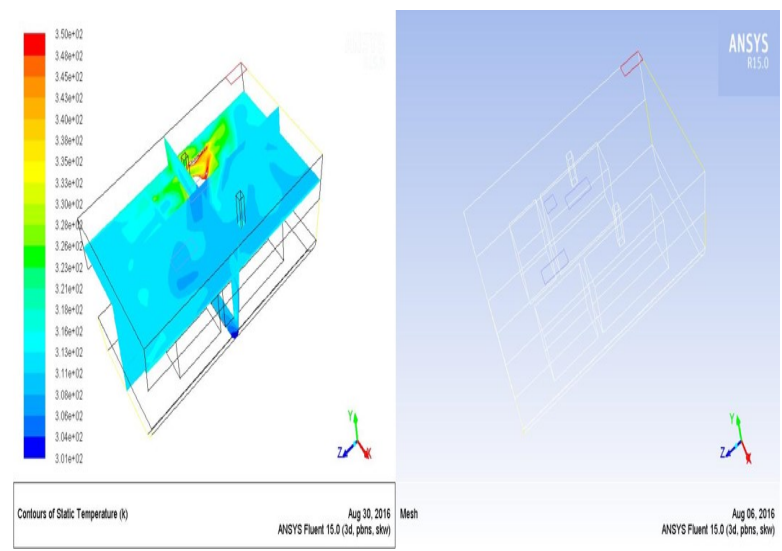

Fig. 9. Isothermal contours of temperature and mesh of case 5

c) Case 6

Inlets are on the generator and diesel engine and outlet is located close to the diesel engine on the engine room ceiling (Figure 10). Although average temperature in this layout has shown a little bit increase compared to case 2, heat concentration is decreased and limited to east part of the diesel engine due to inlets positions far away from the ceiling center. Analysis of the double-vent case with total area of $4.5 \mathrm{~m}^{2}$ indicates that the heat concentrations are not eliminated and there are at least some parts of the engine room deprived from input air circulation for ventilation purposes. Results of simulations in these cases are listed in Table VI.

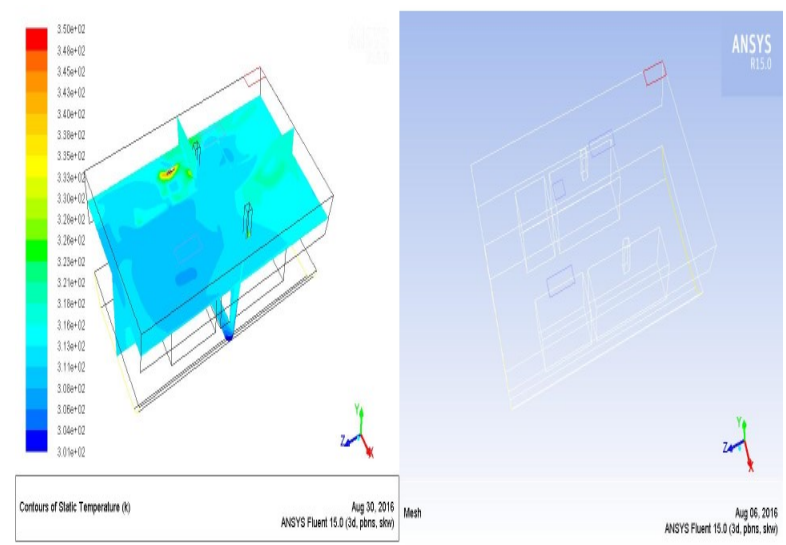

Fig. 10. Isothermal contours of temperature and mesh of case 6

Considering results of the $4.5 \mathrm{~m}^{2}$ single inlet case and three different positioning layouts, it was shown that positioning the inlet above the diesel engine and in the middle of the ceiling are better cases. Considering the double vent case with total area of $4.5 \mathrm{~m}^{2}$, the heat concentration inside the engine room is not eliminated totally. Part of the engine room is deprived of the intake air flow required for cooling purposes. Considering 6 simulations made with a total vent area of $4.5 \mathrm{~m}^{2}$ it could be concluded that the proposed $4.5 \mathrm{~m}^{2}$ area (obtained through ISO 8861 ) is not enough for cooling purposes of the MMR2 engine room. So the entrance vent area will be increased until the desired results are achieved. Hence the next two cases are simulated in the case of $6 \mathrm{~m}^{2}$ vent inlet area. If the proper outcome is not resulted from the $6 \mathrm{~m}^{2}$ single vent, the area could be further increased.

TABLE VI. RESULTS FOR CASES 4-6 WITH DOUBLE INLET

\begin{tabular}{|c|c|c|c|}
\hline Parameter/Case & C.4 & C.5 & C.6 \\
\hline Inlet velocity (m/s) & 5 & 5 & 5 \\
\hline Inlet Area (m) & 4.5 & 4.5 & 4.5 \\
\hline Outlet Area (m $\mathbf{( m}^{\mathbf{2}}$ & 2 & 2 & 2 \\
\hline Average temperature (K) & 315.9 & 313.4 & 314.5 \\
\hline Heat concentration & 0.19 & 0.14 & 0.18 \\
\hline
\end{tabular}

\section{Inlet Area of $6 m^{2}$}

a) Case 7

Inlet is positioned on the diesel engine and Outlet is Outlet vent is located close to the diesel engine on the engine room ceiling (Figure 11). There is a considerable heat concentration around the generator shell due to distance of the inlet from the generator.

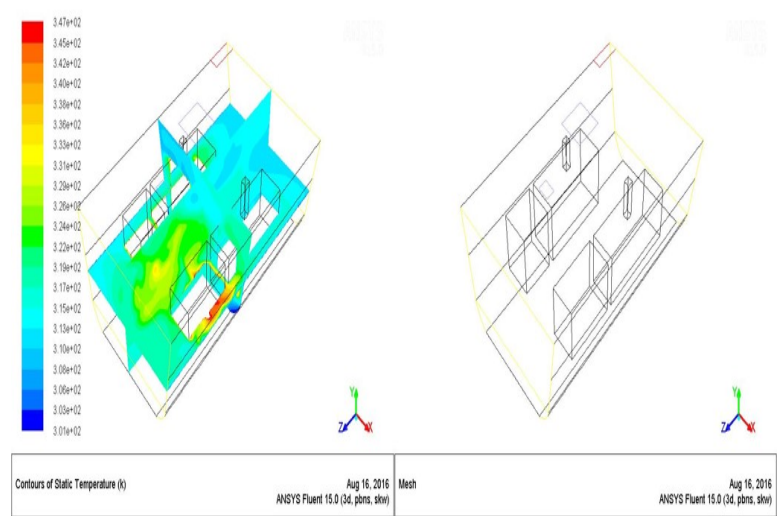

Fig. 11. Isothermal contours of temperature and coordination of inlet and outlet for case 7

\section{b) Case 8}

Inlet is positioned in the ceiling center and outlet is located close to the diesel engine on the engine room ceiling (Figure 12). Both maximum and minimum temperature levels are decreased in this case compared to the previous one. Inlet positioning in the ceiling center still creates heat concentration between equipment and lateral walls of the engine room. Compared to the $4.5 \mathrm{~m} 2$ inlet area and analysis of the $6 \mathrm{~m} 2$ single inlet indicates that despite the improvements made earlier, thermal condition has not become desirable yet Considering $6 \mathrm{~m} 2$ single or double inlet vent, although the average temperature in the engine room decreases, the heat concentration in some points is not eliminated as shown in Table VII. Therefore, various cases of single \& double vents (with total area of $8 \mathrm{~m} 2$ ) with various arrangements are analyzed in the next section. 


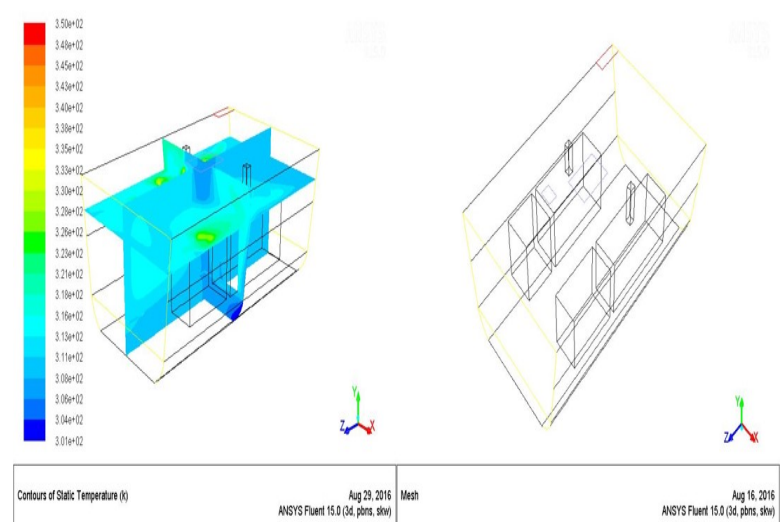

Fig. 12. Isothermal contours of temperature and coordination of inlet and outlet for case 8

\section{Inlet Area of $8 m^{2}$}

a) Case 9

Inlet is positioned on the diesel engine and located close to the diesel engine on the engine room ceiling (Figure 13). Although average temperature in this case is decreased compared to the similar cases of $4.5 \mathrm{~m}^{2}$ and $6 \mathrm{~m}^{2}$, heat concentration has remained the same between equipment and the side walls of the engine room.

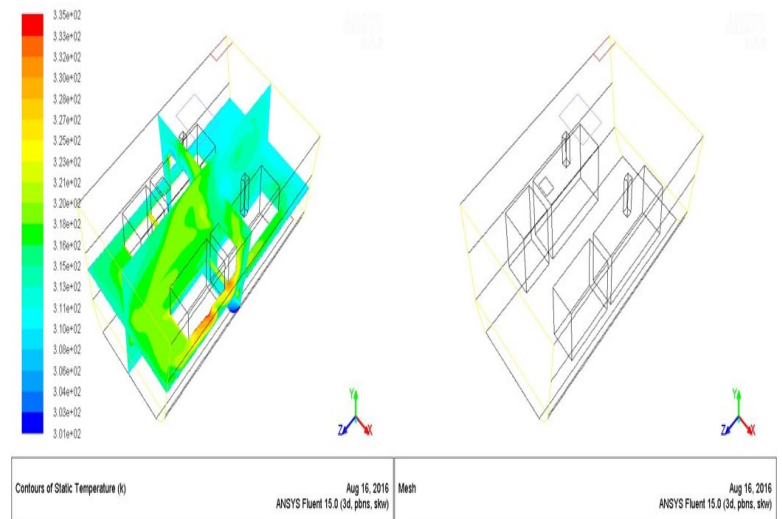

Fig. 13. Isothermal contours of temperature and coordination of inlet and outlet for case 9

TABLE VII. RESULTS FOR CASES 7 - 8

\begin{tabular}{|c|c|c|}
\hline Parameter/Case & C.7 & C.8 \\
\hline Inlet velocity (m/s) & 5 & 5 \\
\hline${\text { Inlet Area } \mathbf{( m}^{\mathbf{2}}}^{\text {Outlet Area }} \mathbf{( m}^{\mathbf{2}}$ & 6 & 6 \\
\hline Average temperature (K) & 2 & 2 \\
\hline Heat concentration & 316.9 & 312.9 \\
\hline
\end{tabular}

b) Case 10

Inlet is located in the ceiling center and outlet is located close to the diesel engine on the ceiling (Figure 14). In spite of the decrease in the average temperature compared to the previous and similar cases with $4.5 \& 6-\mathrm{m}^{2}$ inlet area, there is a considerable heat concentration above the two generators and between generator (for turbine) and side walls as well. Results of simulations in this case are listed in Table VIII.

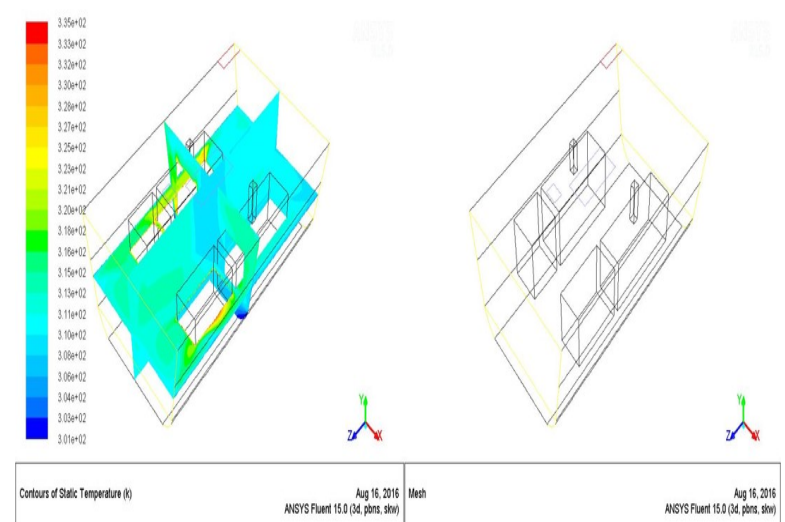

Fig. 14. Isothermal contours of temperature and coordination of inlet and outlet for case 10

TABLE VIII. RESULTS FOR CASES 9 - 10

\begin{tabular}{|c|c|c|}
\hline Parameter/Case & C.9 & C.10 \\
\hline Inlet velocity (m/s) & 5 & 5 \\
\hline Inlet Area $\left.\mathbf{( m}^{\mathbf{2}}\right)$ & 40 & 40 \\
\hline Outlet Area $\left.\mathbf{( m}^{\mathbf{2}}\right)$ & 2 & 2 \\
\hline Average temperature (K) & 314.5 & 312 \\
\hline Heat concentration & 0.062 & 0.058 \\
\hline
\end{tabular}

E. Two Inlet Areas of $4 m^{2}$

Simulations in these cases require two inlets for ventilation air $(308 \mathrm{~K})$ each of which $4 \mathrm{~m}^{2}$. There are four layouts considered for simulation of double inlets as follow.

a) Case 11

Inlets are positioned in the middle of the room above the diesel engine and outlet located close to the diesel engine on the engine room ceiling (Figure 15). Average temperature level is decreased in this case same as the similar aforesaid $4.5 \mathrm{~m}^{2}$ case, however the heat concentration remains the same between diesel and generator (turbine) and the side walls of the engine room and above the generators as well.

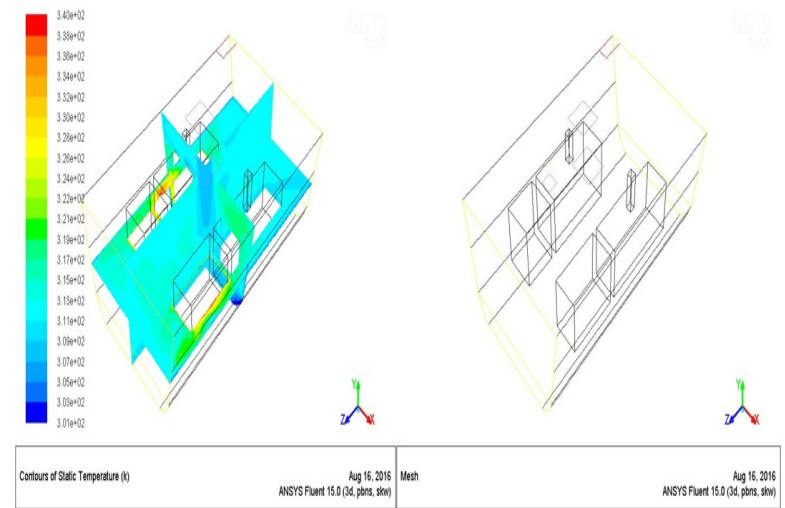

Fig. 15. Isothermal contours of temperature and coordination of inlet and outlet for case 11 


\section{b) Case 12}

Inlets are positioned in the ceiling center and above the generator (for turbine) and outlet is located close to the diesel engine on the engine room ceiling (Figure 16). Heat concentration above the diesel engine and generator (for turbine) is considerably decreased in this case however the concentration has remained the same above the generator.

\section{c) Case 13}

Inlets are positioned above the generator (for turbine) and diesel engine and Outlet vent is located close to the diesel engine on the engine room ceiling (Figure 17). Heat concentration on the diesel engine is completely removed. It is insignificant on the generator however there is considerable heat concentration above the generator (for diesel).

\section{d) Case 14}

Considering outlet vents were close to the diesel engine in all the aforesaid cases, in case 14 inlets are positioned on the diesel engine and turbine (with total area of $8 \mathrm{~m}^{2}$ ) while the outlet is positioned close to the generator (for turbine) (Figure 18). Heat concentration exists in the south part of the generator (for diesel) and generator (for turbine) in this case while it shows considerable decrease in temperature above the equipment and machineries. Further distances between input and output vents, displacement of larger air volumes and better air circulation in the engine room are among the advantages of such layout.

\section{ANALYSIS AND CONCLUSION}

Positioning the inlets on the diesel engine leads to heat concentration around the generator (for turbine) in the single inlet cases while considering position of the outlet vent, input air is not circulated properly. In cases of relocating the inlets to the ceiling center there is a heat concentration in areas between the engine and the room walls as well as zones between generator (for turbine) and the room walls. Analyzing the temperature contours show that air flow is not circulated adequately in such zones. Positioning the inlets above the generator (for turbine) is the optimum case concerning lower average temperature level which is resulted through farther distance between inlet and outlet vents in this case which exposes the engine room to considerable inlet air circulation. However, heat concentration around the diesel engine increases in this case may lead to loss of engine efficiency due to the hot air entering the combustion chamber. The $8 \mathrm{~m}^{2}$ single vent positioned in the ceiling center has shown better conditions compared to other cases. Considering temperature and flow current contours in double inlet cases, average temperature and its level of concentration are lower compared to the single inlet case due to proper circulation of the ventilation air and sweeping hot air away in highly concentrated areas. On the other hand, there are some heat concentrations in case of the double inlet so that it could be shown that the flow rate and current velocity decrease in such areas and ventilation air flow is not properly circulated and accordingly heat concentration increases. Figures 19 and 20 show the parameter $\eta$ and the average temperature of the above studies cases respectively. Although impact of layout, single and double positioning and inlet areas are integrated together, considering aforesaid issues, it could be concluded that the double inlets layout with two $4 \mathrm{~m}^{2}$ inlet area above the turbine and diesel engine has shown better results with respect to heat concentration and flow current pattern compared to all other simulations elaborated earlier in the present study. In the same way heat concentration in this case has shown better improvements compared to other cases

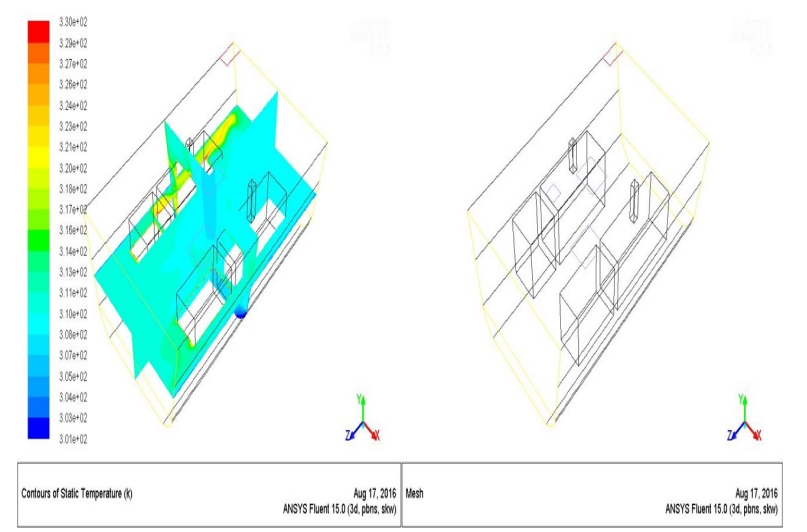

Fig. 16. Isothermal contours of temperature and coordination of inlet and outlet for case 12

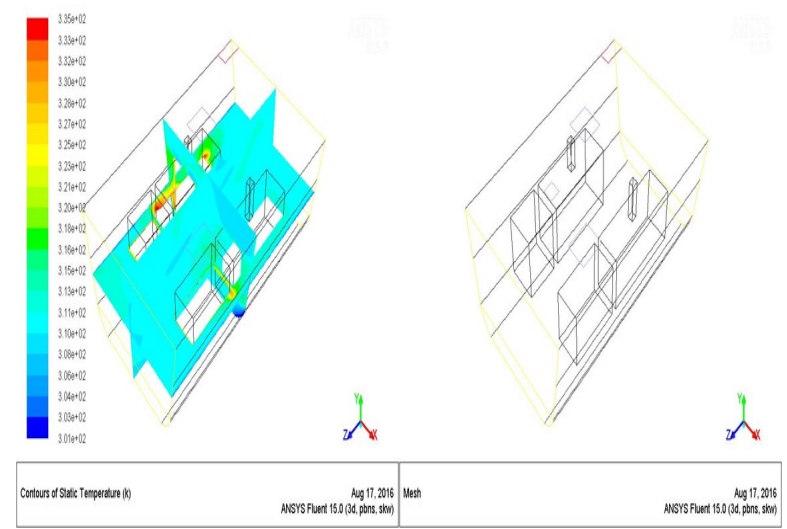

Fig. 17. Isothermal contours of temperature and coordination of inlet and outlet for case 13

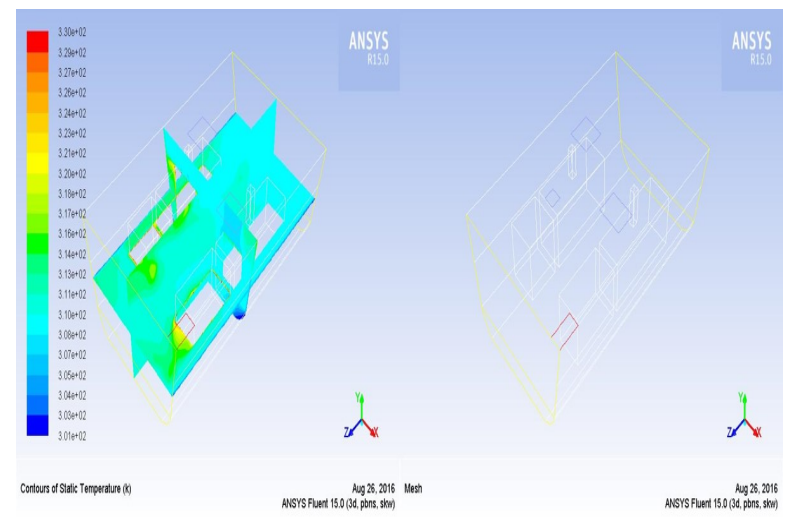

Fig. 18. Isothermal contours of temperature and coordination of inlet and outlet for case 14 
TABLE IX. RESULTS FOR CASES 11 - 14 WITH DOUBLE VENT

\begin{tabular}{|c|c|c|c|c|}
\hline Parameter/Case & C.11 & C.12 & C.13 & C.14 \\
\hline Inlet velocity (m/s) & 5 & 5 & 5 & 5 \\
\hline Inlet Area $\left.\mathbf{( m}^{\mathbf{2}}\right)$ & 8 & 8 & 8 & 8 \\
\hline Outlet Area $\left.\mathbf{( m}^{\mathbf{2}}\right)$ & 2 & 2 & 2 & 2 \\
\hline Average temperature (K) & 313.1 & 310.5 & 311.3 & 310.7 \\
\hline Heat concentration & 0.08 & 0.05 & 0.06 & 0.05 \\
\hline
\end{tabular}

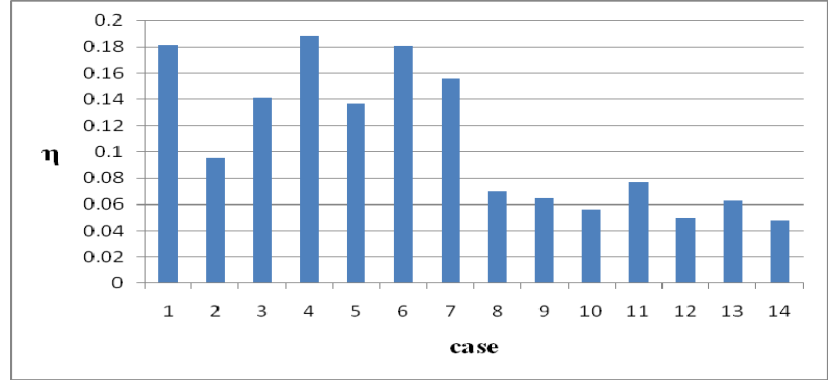

Fig. 19. The graph of $\eta$ for each case

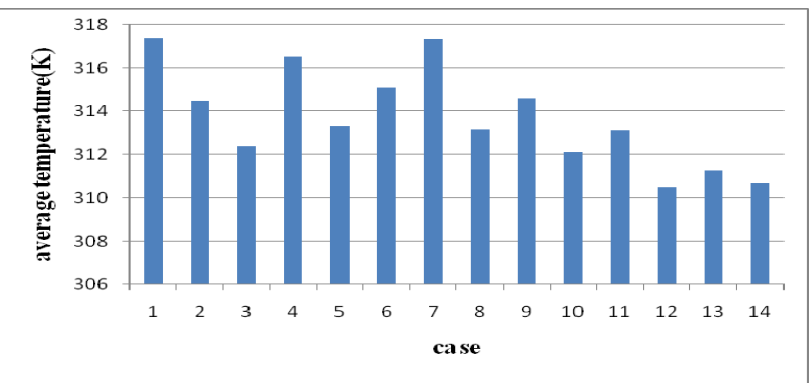

Fig. 20. Graph of average temperature for each case

\section{REFERENCES}

[1] BS EN ISO 8861:1998, Shipbuilding - Engine-room ventilation in diesel engined ships - Design requirements and basis of calculations, British Standards, 1998.

[2] W. Newton, M. Lewis, D. Carswell, N. Lavery, B. Evans, D. Bould, J. Sienz, "Investigating the thermal profile of a marine vessel engine room through simulation with field measurements", Applied Thermal Engineering, Vol. 73, No.1, pp. 1360-1370, 2014

[3] S. Jiang, $\mathrm{X} . \mathrm{Xu}$, "Three-Dimensional Numerical Simulation of the Ventilation System in Closed Engine Rooms Based on CFD”, Chinese Journal of Ship Research, Vol. 2, No. 2, pp. 80-83,89, 2013

[4] H. Lee, H, K. Seo, "Ventilation Analysis for an Engine Room of a Ship", Journal of the Society of Naval Architects of Korea, Vol. 41, No. 5, 2004

[5] Y. C. Liang, Simulation Analysis and Optimization of Ship Engine Room Ventilation System, MSc Thesis, Shanghai Jiaotong University, 2012

[6] W. J. He, Numerical Simulation of Temperature and Velocity Fields in Vessel Engine Room, MSc Thesis, 2006

[7] Y. Jiang, Numerical Simulation of Airflow Distribution in Marine Engine Room Ventilation, MSc Thesis, Harbin Engineering University 2013

[8] J. H. Ding, C. B. Ni, Y. P. He, "CFD Application in Airflow Field Analysis for LNG Ship Engine Room", Proceedings of the 11th Pacific/Asia Offshore Mechanics Symposium, pp. 225-229, 2014

[9] X. J. Li, R. P. Zhou, D. Konovessis, "CFD analysis of natural gas dispersion in engine room space based on multi-factor coupling", Ocean Engineering, Vol. 111, pp. 524-532, 2016
[10] J. A. Perez, J. A. Orosa, T. Grueiro, "A three-dimensional CFD simulation study to reduce heat stress in ships", Thermal Engineering, Vol. 94, pp. 413-421, 2016

[11] J. C. Ramos, M. Beiza, J. Gastelurrutia, A. Rivas, R.Anton, G. S. Larraona, I. de Miguel, "Numerical modelling of the natural ventilation of underground transformer substations", Applied Thermal Engineering, Vol. 51, No. 1-2, pp. 852-863, 2013

[12] P. Rohdin, B. Moshfegh, "Numerical modelling of industrial indoor environments: A comparison between different turbulence models and supply systems supported by field measurements", Building and Environment, Vol. 46, No. 11, pp. 2365 - 2374, 2011

[13] MAN Diesel \& Turbo, MAN V 28/33D STC Project Guide, 2014 